\title{
Gesture Recognition Robot via Kinect Sensor
}

\author{
Mohd.Nazri, Ismail \\ National Defence University of Malaysia, (UPNM), Sungai Besi, Kuala Lumpur \\ Sayed Aziz, Sayed Hussin \\ Universiti Kuala Lumpur(MIIT), 1016, Jalan Sultan Ismail,50250 Kuala Lumpur \\ Mohd Afizi Shukran \\ FSTP, UPNM, Sungai Besi, 50250 Kuala Lumpur
}

\begin{abstract}
This project is designed to develop Gesture Recognition Robot via Kinect Sensor. The idea of this project is starting from research of Kinect on pc. This paper is to provide plenty useful feature of Kinect such as controlling robot by using our gesture and motion. It is a breakthrough in the market as many applications will be using gesture or motion to control it. This project is a startup for various applications of Kinect or any sensors with the same capability to improve daily life.
\end{abstract}

Key words: $\quad$ Gesture Recognition; Kinect; Robot.

\section{Introduction}

In recent years, visual input sensors are incorporated into robotic automation tasks to enhance an application's flexibility, precision or functionality. Yet there are limitations to it, for such as precisely perceive current environment, doing surgery or precision detection. Thus, researchers start to develop gesture-recognition systems to improve the life-style.

The purpose of this project is to build a project to control robot using Kinect motion sensor. The project is aimed to develop a controllable robot with motion and gesture recognition.

In this project, a robot will be connected to a computer which also connected to the Kinect sensor. This system will lets human to control the robot by analyzing the movements of their hand or any gesture, then the robot will replicates those movements almost in real-time.

\section{Literature Review}

Other research that had been developed which is similar to our project is Humanoid Teleoperation with Kinect done by Taylor Veltrop. "In this project, he controls a humanoid

robot, Nao with the Kinect and a game controller. Arms may be controlled with a direct joint based style or inverse kinematics. The robot may be navigated with torso tracking, mouse style leg gestures, or directly with the game pad (for moving forward and backward). If Wiimotes are used in combination with the Kinect, at least 12 degrees of freedom can be controlled with arms "[1].
"We report the development and evaluation of a new interactive humanoid robot that communicates with humans and is designed to participate in human society as a partner. A human-like body will provide an abundance of nonverbal information and enable us to smoothly communicate with the robot. To achieve this, we developed a humanoid robot that autonomously interacts with humans by speaking and gesturing. Interaction achieved through a large number of interactive behaviors, which are developed by using a visualizing tool for understanding the developed complex system" [2]

"Robots are being developed that operate under a wide variety of conditions including unknown, unstructured and dynamic scenarios. Mobility in such scenarios is a key issue to increase the degree of autonomy of a robotic system since it is the basis to incorporate more subsystems and functionalities. Thus, the performance of the motion system strongly affects the task carried out by the vehicle. The capabilities required for the navigation of an autonomous robot are tied up with the specific application and vehicle".[3]

\section{Methodology}

This chapter includes the research that use for the project development. The methodology includes a collection of theories, concepts of ideas as it related to particular discipline or field of inquiry. There are different methods in collecting information or more precisely data gathering. It can be carried out by searching the related topic literatures, white papers, technical papers, conferences proceedings, product data sheets, web pages, project focus groups, conducting interviews 


\section{Yimternational Research Journal}

p-ISSN 2202-2821 e-ISSN 1839-6518 (Australian ISSN Agency)

with experienced personnel, distributing questionnaire, or even communicate to people.

In the system development methodology is refer to the documented collection of guidelines, procedures and standards intended to ensure the development of quality application systems that meet the users' requirements in an efficient manner. The system development methodology involves a series of operations and procedures that are used to develop an application or system. The type of development process model to be used for the project is Spiral model.

The spiral methodology fixes some of the problems introduced by the waterfall methodology. The spiral methodology still has the four phases. A little time is initially spent in each phase followed by several iterations over all four phases.

Simply, the methodology iterates over the processes of think a little, plan a little, implement a little, then test a little. The document structure or deliverable types from each phase do not change in structure but the content is very dynamic. As the methodology progresses more detail is generated. Finally, after several iterations, the product is complete and ready to ship.

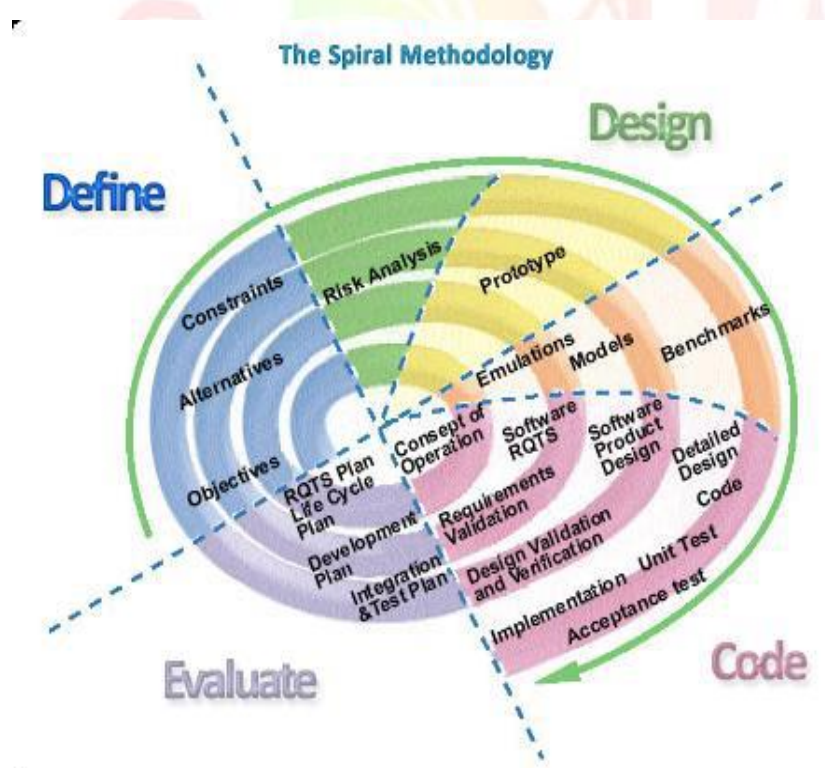

Figure 1: Spiral Model

\section{A. Project Planning}

Project planning phase involves creating a suite of planning documents to help guide the developer throughout the project delivery. This second stage should include a detailed identifications and assignment of each task until the end of project. It should also include a risk analysis and a definition of criteria for the successful completion of each deliverable.
Vol. $06 \mathrm{No}, 012016$

82800601201601

\section{Project Plan}

The creation of a comprehensive Project Plan is critical to the success of the project. It identifies the project phase and task to be undertaken to complete the project. It identifies the sequencing, duration and dependencies of task as well the generic resource and financial expenditures required to complete the project. The gestured controlled robot topology is shown in Figure 2

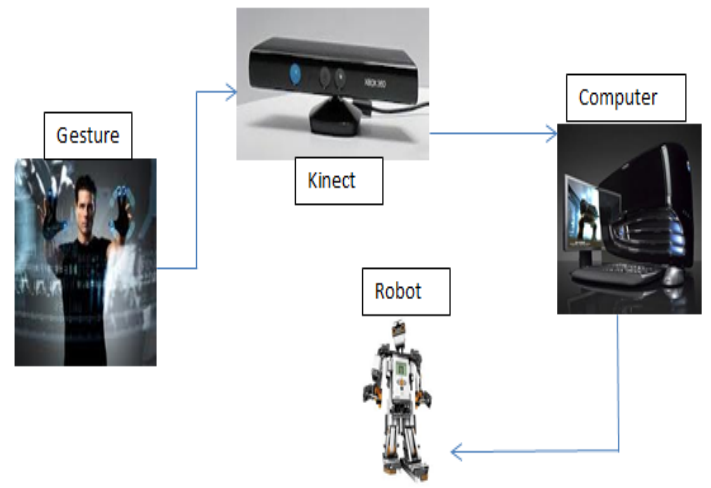

Figure 2: Proposed System Topology

\section{a) Resource Plan}

The detailed assessment of the resources required to undertake the project should be made during this phase. The required as Kinect Sensor, Lego Mindstorm and labor are identified. Timeline and costing also is identifies during this phase.

\section{b) Execution}

This stage involves the execution of each activity and task listed in the project plan. During the process, the plan solution is implemented to solve the problem specified in the project requirements.

a. Setup robot: Robot will be setup, in a humanoid form for better performance.

b. Coding robot and program: The robot module will be code in $\mathrm{C}++$ Language. The program which will support Kinect also will be written in $\mathrm{C}++$ Language.

c. Testing: Do the testing on robot with some gestures.

d. Analysis: Analyze the performance in term of response time and movement of the robot.

\section{c) Project Closure}

Project Closure involved of final result of the system. This project covered a series of activities that includes:

- Assessing whether the objective of the project have been met. 


\section{Yinternational Regearch Journal}

p-ISSN 2202-2821 e-ISSN 1839-6518 (Australian ISSN Agency)

- Identifying the outstanding items (activities and task).

- Listing the activites that required handing over documentation

Final activity can be review as an overall success by how well it performed against the objective in the planning phase.

\section{B. Concept of Operation}

\section{Basic Block Diagram}

Figure 3 shows block diagram of the gesture controlled robot system. This system shows one input, from human in a form of gesture. Then, the Kinect will receive the human gesture and sent it to computer to be interpreted. The output for this system is the robot will react to the human gesture.

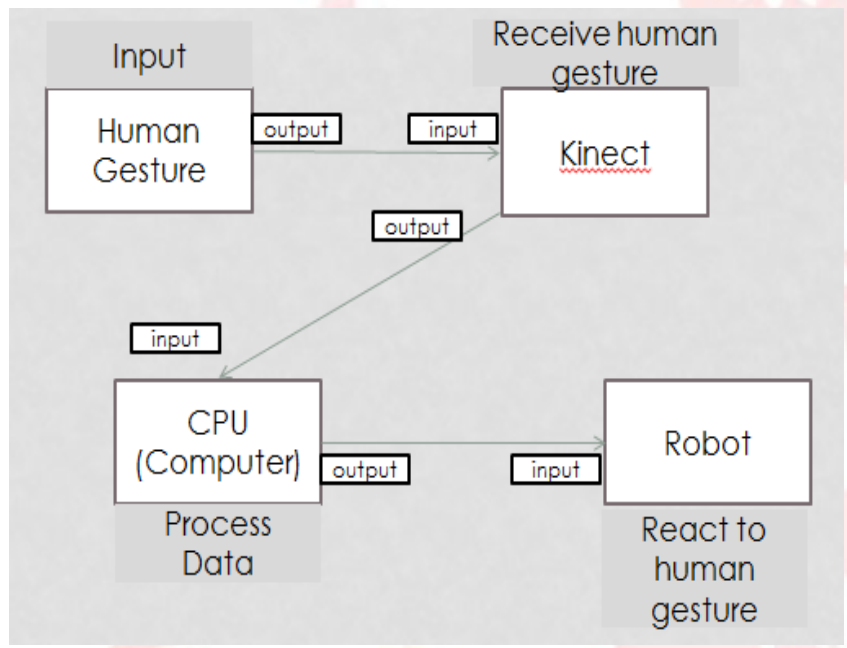

Figure 3: Basic Block Diagram

\section{Operation Flowchart}

Figure 4 shows the flow chart operation explains the process of the system. When the system starts, the Kinect Sensor will be ready to receive any gesture from the user. If there are any gestures, it will be activated and send it to the computer for interpretation and sent it to robot for movement. If not, the Kinect will be idle, waiting for any gestures.

\section{Results}

In this chapter, system prototype was tested to prove that the entire prototype and system requirement is based on the objective and achieve the objective. Once the prototype and the system had been design and code, it should be tested properly. All features of the solution and its output must be tested where comparing the expected output with the actual output, checking the relevance and completeness of the output for the prototype of Gesture Recognition Robot.

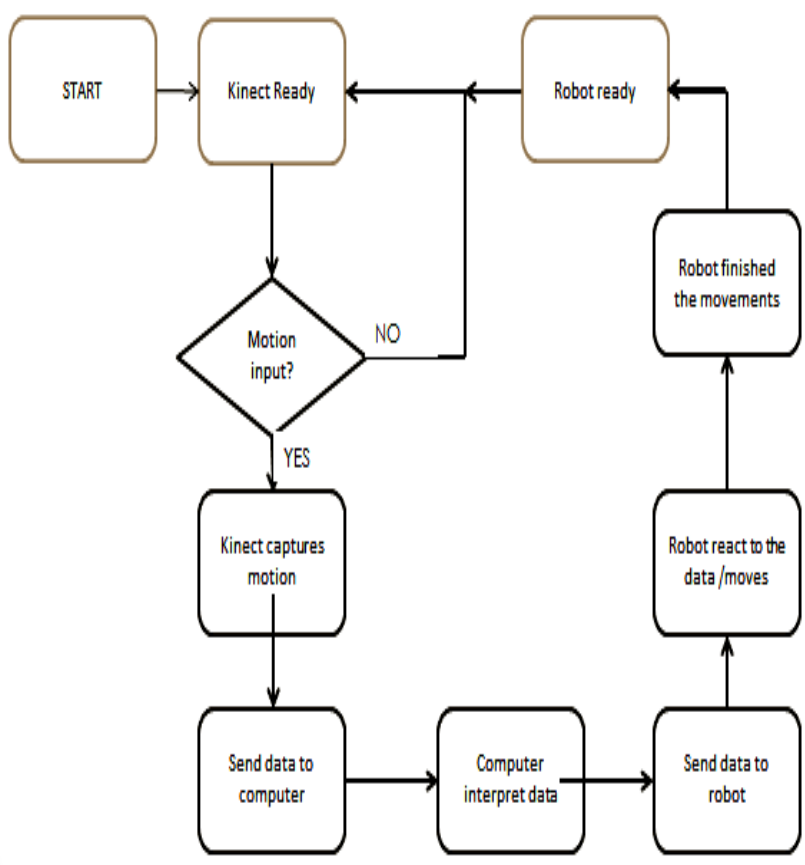

Figure 4: Operational Flow Chart

\section{A. Functionality Test}

During the prototype test, user starts by waving both hands towards to Kinect Sensor. After it recognized the gesture, each hand will be marked as green and red. The robot moves to specific gestures will ensure the system is function correctly.

After the development of the system finish, the system is tested according to the functionality. All the function is tested such as either the system can ready the operation.

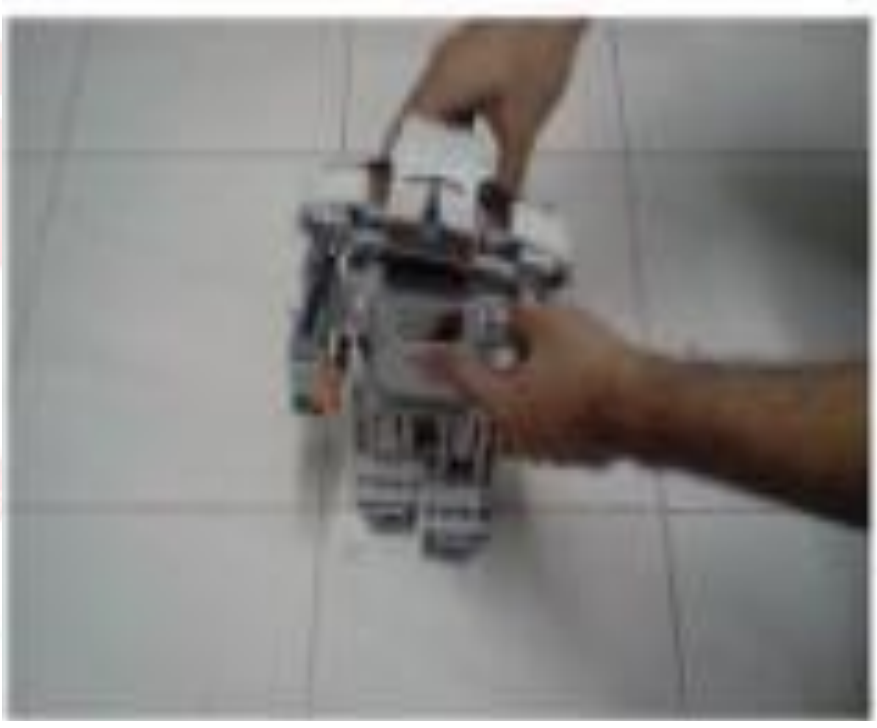

Figure 5: Mindstorm NXT Boot-up

Figure 5 shows of booting up Mindstorm NXT 
p-ISSN 2202-2821 e-ISSN 1839-6518 (Australian ISSN Agency)

Figure 6 shows how to check communication port of Mindstorm NXT by using Bluetooth connection. It is required when choosing communication port in NXT Vehicle Program.

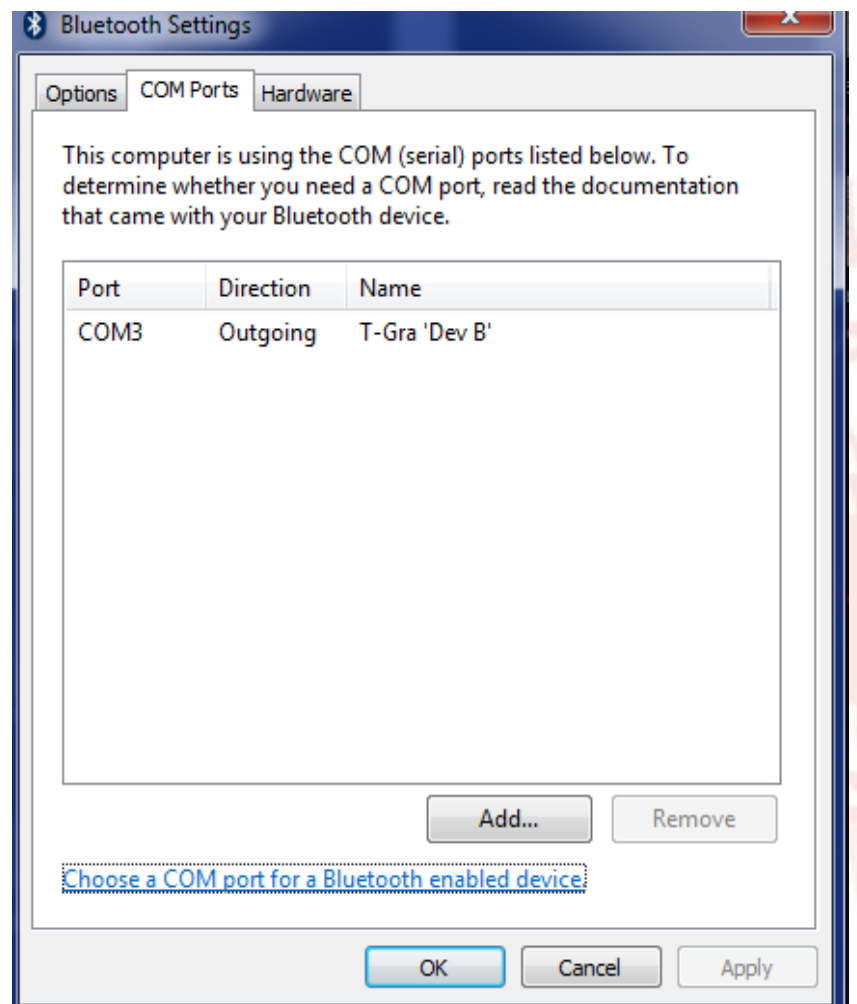

Figure 6: Checking bluetooth connection

Figure 7 shows steps of connecting Mindstorm NXT with computer. Comport 3 was chose as previous figure shows COM3 for Mindstorm NXT bluetooth connection. Pressing connect and the status will change to "Connected".

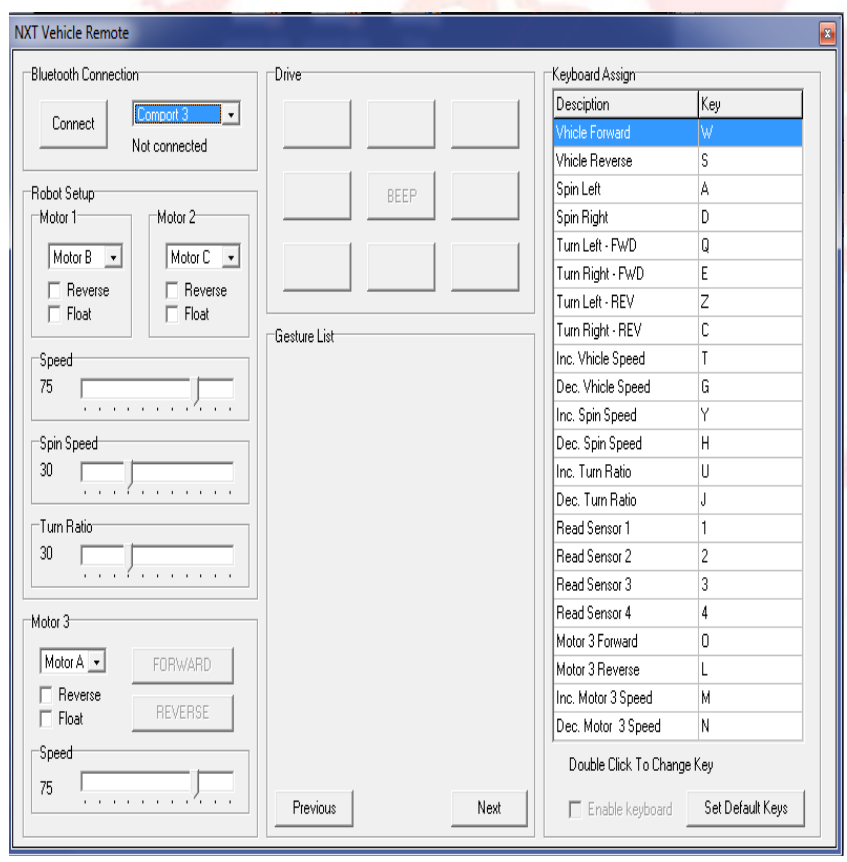

Figure 7: To connect computer with Mindstorm NXT
Vol. 06 No. 012016

82800601201601

Figure 8 shows Kinect connected to computer via USB cable.

Figure 9 shows opening HandKinect software, which ready to accept gesture from user.

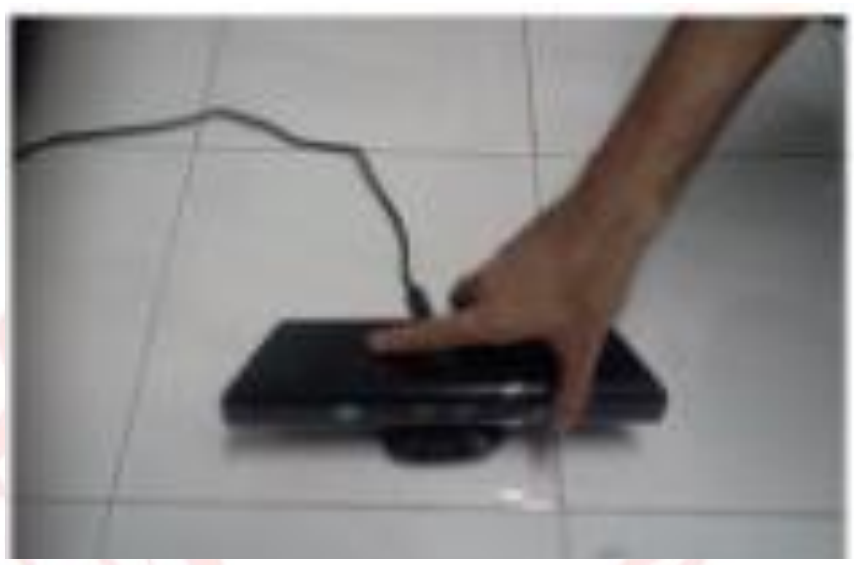

Figure 8: Connect Kinect to computer

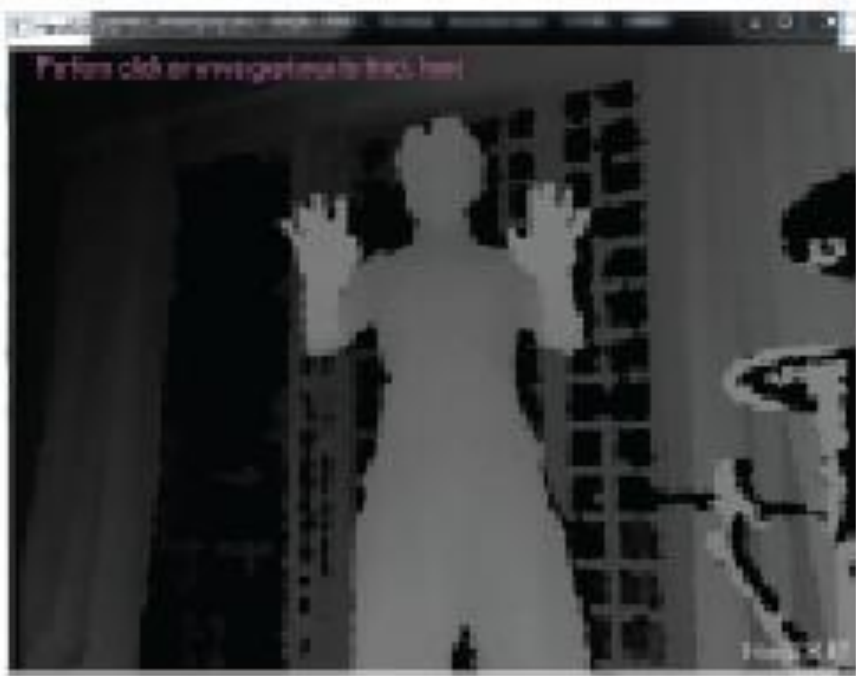

Figure 9: Starting the HandKinect and testing

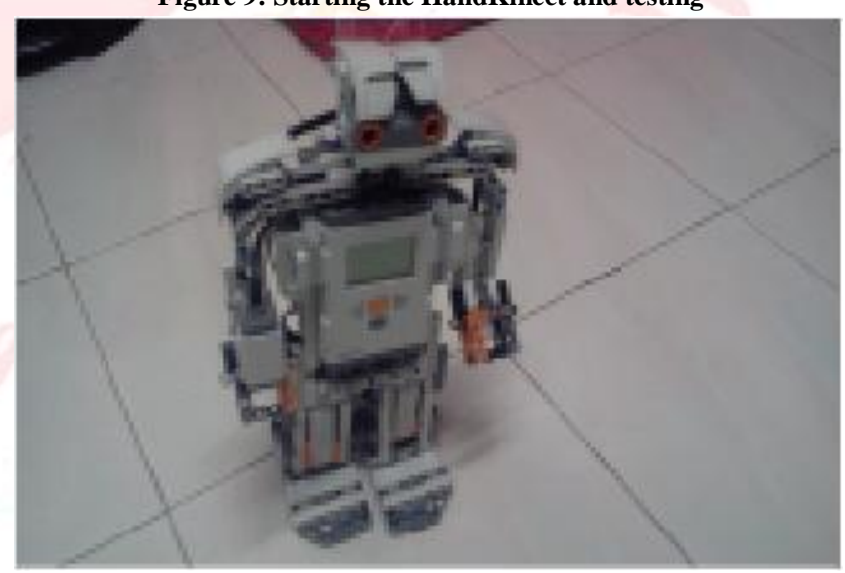

Figure 10: Testing Gesture 


\section{References}

[1]. Taylor Veltrop Website, Available: http://taylor.veltrop.com/robotics.php

[2]. Kinect for Windows.

url:http://research.microsoft.com/enus/um/redmond/projects/kinectsdk/ .

[3]. Kinect Hacks Community. url: http://www.kinecthacks.com

[4]. Takayuki Kanda, Hiroshi Ishiguro, Michita Imai and Tetsuo Ono. Development and Evaluation of Interactive Humanoid Robots. Proceedings of the IEEE, VOL 92, No.11, November 2004.

[5]. Kinect for Windows.

url:http://research.microsoft.com/enus/um/redmond/projects/kinectsdk/

[6]. Kinect Hacks Community.

Available: http://www.kinecthacks.com

[7]. Luis Montesano, Jayier Minguez and Luis Montano, Lessons Learned in Intergration for Sensor Based Robot Navigation System. International Journal of Advanced Robotic Systems 